\title{
Serum anticyclic citrullinated protein antibody titers are correlated with the response to biological agents in patients with rheumatoid arthritis
}

\author{
This article was published in the following Dove Press journal: \\ Open Access Rheumatology: Research and Reviews \\ 16 May 2014 \\ Number of times this article has been viewed
}

\author{
Ryo Takahashi \\ Sakiko Isojima \\ Masayu Umemura \\ Yoko Miura \\ Nao Oguro \\ Syo Ishii \\ Shinya Seki \\ Takahiro Tokunaga \\ Hiroyuki Tsukamoto \\ Hidekazu Furuya \\ Ryo Yanai \\ Tsuyoshi Kasama \\ Division of Rheumatology, \\ Department of Medicine, Showa \\ University School of Medicine, \\ Tokyo, Japan
}

\begin{abstract}
Anticyclic citrullinated protein antibody (ACPA) is known as an important indicator for diagnosis of rheumatoid arthritis (RA). Our aim was to examine the relationship between the serum ACPA titer at baseline and responsiveness to biological agents (antagonists of either tumor necrosis factor or interleukin 6) in patients with RA. ACPA was measured using second-generation chemiluminescent enzyme immunoassay. Disease activity was assessed using disease activity scores 28 . Fifty-seven RA patients with biological agents were enrolled, and the median ACPA titer at baseline was $110.0 \mathrm{U} / \mathrm{mL}$. The median ACPA titer was $23.3 \mathrm{U} / \mathrm{mL}$ and $183.0 \mathrm{U} / \mathrm{mL}$ in the good and moderate response groups, respectively, which were significantly lower than in the no response group $(404.0 \mathrm{U} / \mathrm{mL})$. In addition, $69.2 \%$ and $26.9 \%$ of patients with low $(<100 \mathrm{U} / \mathrm{mL})$ and moderate $(100-499 \mathrm{U} / \mathrm{mL})$ basal ACPA titers showed a moderate to good response. Of the patients with higher $(\geq 500 \mathrm{U} / \mathrm{mL})$ basal ACPA titers, only $14.0 \%$ and $42.5 \%$ showed a good or moderate response, respectively. The remission rate was $77.8 \%$ in the ACPA-negative, which was significantly higher than the rate of $25 \%$ in the ACPA-positive patients. The results suggest that the ACPA titers are correlated with the efficacy of the biological agents used in patients with RA.
\end{abstract}

Keywords: biological agents, remission

\section{Introduction}

Rheumatoid arthritis (RA) is a chronic, progressive disease with an estimated worldwide prevalence of $0.1 \%-1 \%$, and it requires an early diagnosis and aggressive treatment to minimize morbidity. ${ }^{1-3}$ Biological agents such as antagonists of tumor necrosis factor (TNF) or interleukin 6 (IL-6) have been successful in reducing the production of other inflammatory mediators, inducing rapid clinical improvement and remission in RA patients. ${ }^{4-6}$ Furthermore, these patients may experience severe adverse effects, ${ }^{7}$ and the high cost of these agents puts them out or reach of many RA patients. Consequently, identification of early predictors of the response to biological agents would likely have important clinical and economic benefits for RA patients.

Anticyclic citrullinated protein antibody (ACPA) is an antibody against the cyclic citrullinated peptide that was first reported by Schellekens et al in 1998. ${ }^{8,9}$ Although many aspects of the corresponding antigens in the body remain poorly understood, several types of protein have been shown to be potential autoantigens, including citrullinated fibrinogen in RA pannus tissues. ${ }^{10,11}$ Furthermore, ACPA immune complexes
Correspondence: Tsuyoshi Kasama Division of Rheumatology, Department of Medicine, Showa University School of Medicine, 1-5-8 Hatanodai, Shinagawa-ku, Tokyo 142-8666, Japan

Tel +8I 337848942

Fax +8I 337848946

Email tkasama@med.showa-u.ac.jp 
are thought to play major roles in the immunological pathogenesis of RA. ${ }^{12}$ ACPA has been widely measured in clinical practice due to its high disease specificity for $\mathrm{RA},{ }^{13,14}$ and thereby serves as an early diagnostic marker, ${ }^{15}$ and furthermore a predictive factor for joint destruction, ${ }^{16-20}$ which aids in the diagnosis of RA.

In this study, we evaluated whether the disease activity and the individual laboratory test results, especially the serum ACPA level before the initiation of biological therapy, are correlated with responses to biological agents (antagonists of either TNF or IL-6) treatment in RA patients.

\section{Materials and methods \\ Patients}

The study design was a prospective observational cohort study. Fifty-seven patients with RA, who fulfilled the 1987 American College of Rheumatology criteria, ${ }^{21}$ were enrolled in our study between July 2006 and January 2010. All patients had active RA that failed to respond to treatment with methotrexate (MTX), prednisolone, or other disease-modifying antirheumatic drugs (DMARDs). The administered biological agents were infliximab (IFX) in 27, etanercept (ETN) in 17, adalimumab (ADA) in seven, and tocilizumab (TCZ) in six patients. Only biological agent-naïve patients were included. In the period of study (12-14 weeks from administration of biological agents), there was no alteration of their doses of medications including MTX, other DMARDs, and prednisolone as well as biological agents.

\section{Samples}

Serum levels of ACPA, rheumatoid factor (RF), C-reactive protein (CRP), and matrix metalloproteinase-3 (MMP-3) were measured before administration of the biological agents, and the disease activity score (DAS) 28-CRP was evaluated before and 14 (for IFX) or 12 weeks (for ETN, ADA, and TCZ) after administration. According to the European League against Rheumatism response criteria, ${ }^{22}$ all 57 patients were classified into one of the following three groups: 1) good response, 2) moderate response, and 3) no response. The percent improvement in DAS28 from baseline was calculated as follows: (baseline DAS28 - post-treatment DAS28 [12 or 14 weeks]/ baseline DAS28) $\times 100$. In each group, the levels of ACPA, RF, CRP, MMP-3, and DAS28 were assessed before administration of the biological agents to determine if they were associated with treatment responses. Remission was defined as DAS28 $<2.6$ after 12 or 14 weeks of treatment. Patients were divided into three groups according to the ACPA levels before the administration of biological agents: 1 ) low titer (ACPA $<100$
$\mathrm{U} / \mathrm{mL}), 2$ ) moderate titer (ACPA $=100-499 \mathrm{U} / \mathrm{mL})$, and 3) high titer (ACPA $\geq 500 \mathrm{U} / \mathrm{mL}$ ). Responses to treatment were compared among these three groups.

Serum RF, MMP-3, and CRP levels and erythrocyte sedimentation rate were determined using a latex photometric immunoassay and the Westergren method, respectively. The titers of ACPA were measured using commercially available second-generation chemiluminescent enzyme immunoassay kits (STACIA ${ }^{\circledR}$ MEBLux $^{\text {TM }}$ CCP test, Medical and Biological Laboratories, Aichi, Japan). Anti-CCP antibody levels were considered to be positive at a cutoff value of $>4.5 \mathrm{U} / \mathrm{mL}$. The serum was further diluted to determine the titers of ACPA for patients with antibody levels that reached the plateau of the standard.

All experiments were carried out in accordance with protocols approved by Showa University School of Medicine. Human Subjects Research Committee human experiments were performed in accordance with the Declaration of Helsinki, and informed consent was obtained from all patients.

\section{Statistical analysis}

Data were expressed as the means \pm standard deviation or median (range). The relationship between ACPA titers and either the RA disease activity or the indicated measures was evaluated using the Spearman rank correlation. Different groups were compared using the two-sided Kruskal-Wallis nonparametric test and a multiple comparison test (Scheffe's $F$-test). Follow-up tests were conducted using the Bonferroni approach. The Mann-Whitney's $U$ and Fisher's exact tests were used to compare categorical variables, the treatment responses, remission statuses between the ACPA-positive and -negative patients, and the treatment responses among the groups based on ACPA titers. A $P$-value of $<0.05$ was considered to indicate a statistically significant difference for all analyses.

\section{Results \\ Clinical characteristics and clinical responses of patients with RA}

Table 1 shows the clinical background and laboratory test results of the 57 patients enrolled in this study. Also, medication summaries including mean doses of MTX and prednisolone and nonbiological DMARDs with biological agents is listed in Table 2. ACPA before administration of the biological agents was positive in $84.1 \%$ of patients (48/57), and the median value was $110.0 \mathrm{U} / \mathrm{mL}$ (range; 0-4,985.0). Positive correlations were observed between the baseline ACPA and DAS28 and between the ACPA and RF 
Table I Baseline patient characteristics

\begin{tabular}{ll}
\hline Patients (female:male) & $57(5 \mathrm{I}: 6)$ \\
Age (years) & $55.6 \pm 14.8$ \\
Duration of RA (years) & $8.2 \pm 3.2$ \\
MTX dose (mg/week) & $6.0 \pm 3.3(0-10.0)$ \\
DAS28-CRP & $5.42 \pm 1.50$ \\
CRP $(\mathrm{mg} / \mathrm{dL})$ & $1.9(0.04-18.4)$ \\
ACPA $(\mathrm{U} / \mathrm{mL})$ & $110.0(0.0-4,985.0)$ \\
MMP-3 $(\mathrm{ng} / \mathrm{mL})$ & $177.0(44.4-800.0)$ \\
RF $(\mathrm{U} / \mathrm{mL})$ & $60.1(0.00-1,630.00)$ \\
\hline
\end{tabular}

Note: The table shows the clinical background and laboratory test results of the 57 patients enrolled in this study.

Abbreviations: ACPA, anticyclic citrullinated protein antibody; CRP, C-reactive protein; DAS28-CRP, disease activity score 28-C-reactive protein; MMP-3, matrix metallopeptidase-3; MTX, methotrexate; RA, rheumatoid arthritis; RF, rheumatoid factor.

(DAS28: Spearman's rank correlation coefficient $\left[r_{s}\right]=0.53$; RF: $r=0.58$ ). Table 3 shows the backgrounds of subgroups with clinical responses in all patients. Also remission (DAS28 <2.6) was achieved in $33.3 \%$ of patients $(19 / 57)$. There were no significant differences in patient background factors including doses of MTX and prednisolone, tender joint counts, swollen joint counts, CRP, and visual analog scale-general health among the groups (Table 3). ACPA, CRP, RF, and MMP-3 levels were compared among the groups before the administration of biological agents. The median ACPA levels were $23.3 \mathrm{U} / \mathrm{mL}(0-509.0)$ in the good response group, $183.0 \mathrm{U} / \mathrm{mL}(0.6-2,390.0)$ in the moderate response group, and $404.0 \mathrm{U} / \mathrm{mL}(69.0-4,985.0)$ in the no response group, showing a significantly higher level in the no response group than in the other two groups (Figure 1A) $(P<0.05, P<0.01)$. Also, when patients were divided into two groups by the baseline DAS28 as high disease activity (DAS28 >5.1) or not, the difference between the good to moderate response group and the no response group was statistically significant $(P<0.05)$ in the group of either baseline low disease activity (DAS28 $<5.1$ ) or high disease activity. Interestingly, there was also a significant negative

Table 2 Summary of medication in each biological agent group

\begin{tabular}{lllll}
\hline $\begin{array}{l}\text { Biological } \\
\text { agents (n) }\end{array}$ & IFX (27) & ETN (17) & ADA (7) & TCZ (6) \\
\hline MTX (\%) & 96.2 & 41.2 & 85.7 & 66.7 \\
$\quad$ mg/week & $6.96 \pm 1.69$ & $2.82 \pm 3.67$ & $6.57 \pm 2.99$ & $5.0 \pm 3.94$ \\
Prednisolone (\%) & 42.9 & 50.0 & 55.5 & 52.9 \\
$\quad$ mg/day & $1.79 \pm 2.22$ & $0.79 \pm 1.59$ & $2.21 \pm 2.19$ & $2.33 \pm 2.04$ \\
Nonbiological & SASP (5) & SASP (I) & BUC (I) & SASP (I) \\
DMARDs (n) & BUC (3) & & & \\
\hline
\end{tabular}

Note: Each nonbiological DMARD was concomitantly administrated with biological agents.

Abbreviations: ADA, adalimumab; BUC, bucillamine; DMARDs, disease-modifying antirheumatic drugs; ETN, etanercept; IFX, infliximab; MTX, methotrexate; SASP, salazosulfapyridine; TCZ, tocilizumab. correlation $\left(r_{s}=-0.54\right)$ between the percent improvement in DAS28 and the baseline ACPA titers.

Furthermore, there was a significant difference $(P<0.005)$ in ACPA titers between the remission group $(89.9 \mathrm{U} / \mathrm{mL})$ and the no remission group $(402.6 \mathrm{U} / \mathrm{mL})$. Moreover, ACPA levels tended to be lower in the good response group than in the moderate response group. It was suggested that a poorer treatment response may accompany higher ACPA levels before treatment initiation. There were no significant differences in basal MMP-3 or RF levels between the groups before the initiation of biological therapy (Figure 1C and D). Although serum CRP levels tended to be higher in those with poorer treatment responses, the median CRP levels were $1.7 \mathrm{mg} / \mathrm{dL}$ (0.04-12.0), $2.0 \mathrm{mg} / \mathrm{dL}(0.04-8.1)$, and $2.4 \mathrm{mg} / \mathrm{dL}$ (0.14-18.4) in the good response, moderate response, and no response groups, respectively, showing no significant differences among the three groups $(P=0.92)$ (Figure 1B).

\section{Evaluation of clinical responses with baseline ACPA levels}

Based on pretreatment ACPA levels, the patients were divided into a low titer group with ACPA $<100 \mathrm{U} / \mathrm{mL}$ $(\mathrm{n}=26)$, a moderate titer group with ACPA $=100-499 \mathrm{U} / \mathrm{mL}$ $(\mathrm{n}=24)$, and a high titer group with ACPA $\geq 500 \mathrm{U} / \mathrm{mL}(\mathrm{n}=7)$. Treatment responses were compared among these three groups. The low titer group was composed of 18 patients with good responses (69.2\%), seven with moderate responses (26.9\%), and one with no response (3.8\%), ie, a moderate or better response was observed in all but one patient. However, the high titer group was composed of one patient with a good response (14.0\%), three patients with moderate responses $(42.5 \%)$, and three patients with no response (42.5\%). In addition, when the patient group was divided into two groups, by $200 \mathrm{U} / \mathrm{mL}$ of ACPA titer, there was also a significant difference $(P<0.005)$ between the higher ACPA group $(\geq 200 \mathrm{U} / \mathrm{mL})$ and the lower group $(<200 \mathrm{U} / \mathrm{mL})$. Higher basal ACPA levels were associated with no response to treatment $(P<0.01)$, as shown in Figure 2A. In addition, the remission rates showed a tendency to associate with basal ACPA levels although it did not reach statistical significance (Figure 2B). Moreover, out of nine ACPA-negative patients, seven showed good responses $(77.8 \%)$ and two showed moderate responses (22.2\%). Moderate or better responses were observed in all ACPA-negative patients (Table 4). When remission rates were compared between the ACPApositive $(n=48)$ and ACPA-negative $(n=9)$ patients, the rate in the latter was $77.8 \%(7 / 9)$, which was significantly higher than the rate of $25 \%(12 / 48)$ in the former $(P<0.005)$. In 
Table 3 Backgrounds of subgroups with clinical responses in RA patients administered with biological agents

\begin{tabular}{|c|c|c|c|c|}
\hline & Good response & Moderate response & No response & $P$-value \\
\hline Female:male & $22: 3$ & $23: 2$ & $6: 1$ & NS \\
\hline Age, years (range) & $53.2 \pm 14.3(23-75)$ & $56.0 \pm 15.4(27-79)$ & $62.6 \pm 14.6(36-80)$ & NS \\
\hline Duration, years (range) & $7.8 \pm 4.2(0.5-\mid 4.2)$ & $8.5 \pm 3.2(0.8-15.8)$ & $8.3 \pm 4.3(1.0-20.4)$ & NS \\
\hline \multicolumn{5}{|l|}{ Dosages of } \\
\hline MTX, mg/week (range) & $5.9 \pm 3.3(0.0-10.0)$ & $6.7 \pm 2.3(0.0-8.0)$ & $5.6 \pm 3.2(0.0-8.0)$ & NS \\
\hline Prednisolone, mg/day, (range) & $2.68 \pm 3.09(0.0-7.5)$ & $2.94 \pm 3.10(0.0-10.0)$ & $2.87 \pm 2.72(0.0-8.0)$ & NS \\
\hline \multicolumn{5}{|l|}{ ACPA } \\
\hline Positive (\%) & 19/26 (73.1) & $23 / 25(92.0)$ & $6 / 6(100.0)$ & 0.09 \\
\hline Median & 23.3 & 183.0 & 404.0 & $<0.05$ \\
\hline DAS28 at baseline & $4.95 \pm 1.33$ & $5.74 \pm 1.39$ & $5.97 \pm 1.96$ & 0.07 \\
\hline TJC, n (range) & $4.8 \pm 1.8(I-8)$ & $5.4 \pm 2.2(I-I I)$ & $5.8 \pm 4.1(2-12)$ & NS \\
\hline SJC, n (range) & $3.5 \pm 1.6(I-8)$ & $3.1 \pm 1.5(I-6)$ & $3.5 \pm 1.5(2-6)$ & NS \\
\hline VAS-GH, mm (range) & $63.5 \pm 18.3(42.0-80.0)$ & $58.0 \pm 18.4(24.0-89.0)$ & $60.6 \pm 16.3(43.0-88.0)$ & NS \\
\hline CRP, mg/mL (range) & $2.67 \pm 2.82(0.2-6.9)$ & $2.92 \pm 2.65(0.2-8.1)$ & $7.27 \pm 7.62(0.1-18.4)$ & NS \\
\hline DAS28 at 12 or 14 weeks & $2.23 \pm 0.68$ & $4.00 \pm 1.00$ & $5.36 \pm 1.43$ & $<0.01$ \\
\hline
\end{tabular}

Notes: There were no significant differences in patient background factors including doses of MTX and prednisolone, DAS28 components between the groups, except for ACPA titers.

Abbreviations: ACPA, anticyclic citrullinated protein antibody; CRP, C-reactive protein; DAS28, disease activity score 28; MTX, methotrexate; RA, rheumatoid arthritis; SJC, swollen joint counts; TJC, tender joint counts; VAS-GH, visual analog scale-general health.

addition, the ACPA titer was $20.1 \mathrm{U} / \mathrm{mL}(0.0-509.0)$ in the group with remission at 14 weeks, though significant higher titers of ACPA (174.5 U/mL [0.6-4,985.0]) were observed in those who had no remission $(P<0.01)$.

Of the 27 patients started on IFX therapy, 12 had good responses, 12 had moderate responses, and three had no response, with remission being achieved in ten of the 27 patients (37.0\%). The median pretreatment ACPA levels were $20.75 \mathrm{U} / \mathrm{mL}(0.0-166.0), 207.0 \mathrm{U} / \mathrm{mL}(0.6-130.0)$, and $213.0 \mathrm{U} / \mathrm{mL}(69.0-774.0)$ in the good response, moderate response, and no response groups, respectively, showing significant differences among the three groups $(P<0.005)$. As with the overall trend, treatment response was shown to be poorer with higher ACPA levels. Moreover, the median ACPA levels in patients receiving IFX were $2.1 \mathrm{U} / \mathrm{mL}(0-269.0)$ in those experiencing remission and $199.0 \mathrm{U} / \mathrm{mL}(11.9-2,390.0)$ in those without remission, again showing pretreatment ACPA levels to be significantly lower in the former. For the 17 patients started on ETN therapy, the median ACPA levels were $68.0 \mathrm{U} / \mathrm{mL}(29.7-509.1)$ in five with good responses, $151.0 \mathrm{U} / \mathrm{mL}(87.0-500.0)$ in nine with moderate responses, and $404.0 \mathrm{U} / \mathrm{mL}(310.0-4,985.0)$ in three with no response. Similarly, in ADA $(n=7)$ and TCZ $(n=6)$ groups, four and four had good responses and median ACPA titers were $28.5 \mathrm{U} / \mathrm{mL}$ and $12.2 \mathrm{U} / \mathrm{mL}$, respectively; two and two had moderate responses and were $85.0 \mathrm{U} / \mathrm{mL}$ and $140.3 \mathrm{U} / \mathrm{mL}$, respectively; and one in the ADA group had no response and ACPA was $500 \mathrm{U} / \mathrm{mL}$. Although there were no significant differences among the three groups, as with IFX, a poorer treatment response was shown to be associated with higher ACPA levels.

\section{Discussion}

We evaluated whether serum markers and disease activity at baseline could be correlated with responses to treatment with biological agents (antagonists of TNF and IL-6). Herein, we demonstrated that only serum ACPA levels could be correlated with treatment responses as well as improvement rates at 12 or 14 weeks after treatment with biologics. CRP, MMP-3, and RF were not correlated with a treatment response. Moreover, remission was achieved in many ACPA-negative patients, whereas treatment responses in ACPA-positive patients were shown to be poorer in those with higher ACPA levels.

Braun-Moscovici et al reported that a pretreatment level of ACPA $>100 \mathrm{U} / \mathrm{mL}$ predicted a poor response to IFX treatment, which is consistent with our results. ${ }^{23}$ There have also been several reports that focused on whether immunological tests for patients receiving IFX can predict their response to treatment. In contrast to the present study, some reports demonstrated that the occurrence of a treatment response was not associated with the baseline ACPA titers. ${ }^{24-26}$ Potter et al, who simultaneously analyzed ACPA, reported that ACPA did not significantly correlate with treatment response. ${ }^{26}$ However, because treatment response was determined 1 year after the initiation of biological therapy in these studies, their results are not sufficient to establish predictive factors for early treatment responses. Furthermore, 
A

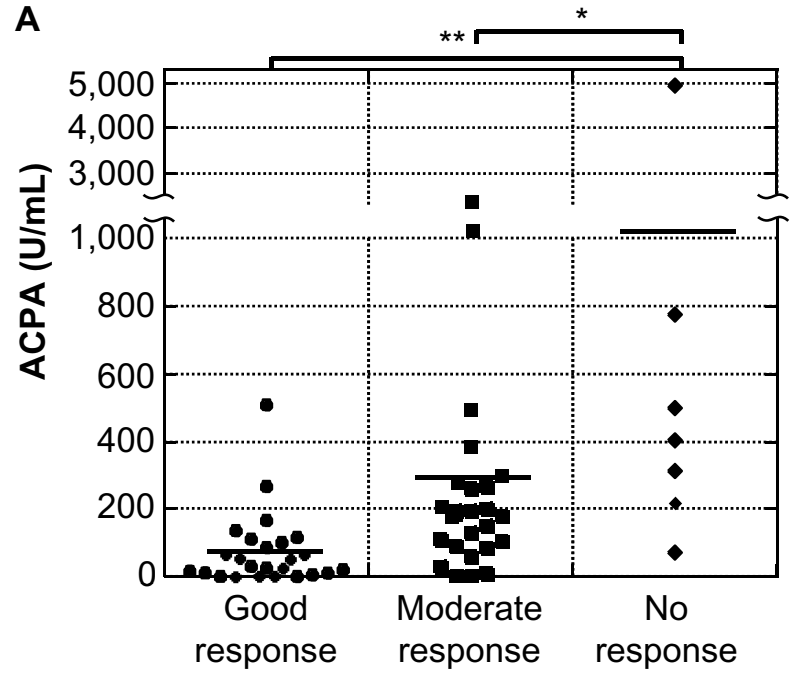

C

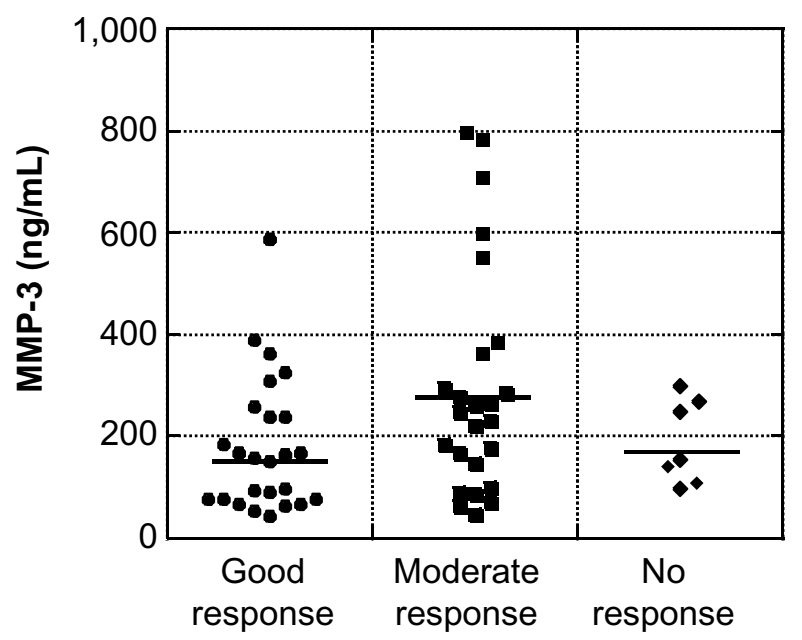

B

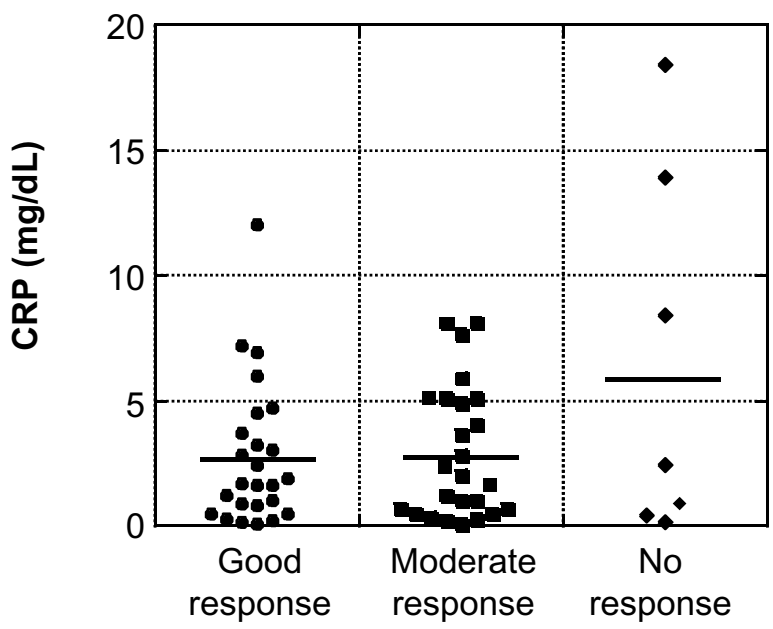

D

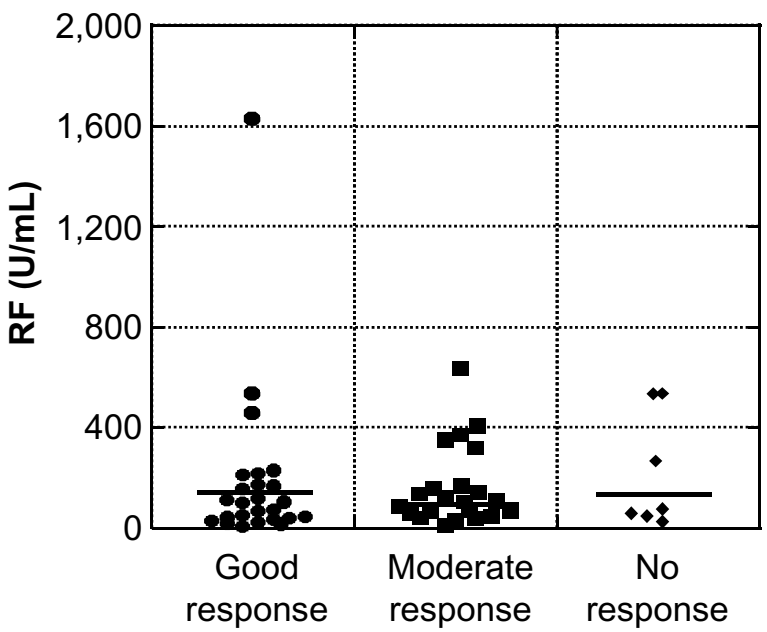

Figure I Serum parameters in subgroups with clinical responses of RA patients administered biological agents.

Notes: The figure shows anticyclic citrullinated protein antibody (ACPA) (A), C-reactive protein (CRP) (B), matrix metallopeptidase-3 (MMP-3) (C), and rheumatoid factor (RF) (D). According to the EULAR response criteria, all RA patients were classified into one of the following three groups: I) good response, 2) moderate response, and 3) no response. ACPA, CRP, MMP-3, and RF levels before administration of the biological agents were compared among the groups. Each symbol represents an individual patient. There were significant differences between the no response group and the other two groups (ACPA) $(\mathbf{A}) ; * P<0.05 ; * * P<0.01$.

Abbreviations: EULAR, European League against Rheumatism; RA, rheumatoid arthritis.

the group analyzed included not only biologics-naive but biologics-failure patients, in contrast with our present study, which included only biologics-naive patients. Similar to our study, Klaasen et al compared disease activity before treatment with that at the 16 th week after treatment initiation in 101 patients receiving IFX and reported that immunoglobulin M-ACPA and RF before treatment initiation were useful for predicting treatment response. ${ }^{27}$ In addition, there are some conflicting observations between basal levels of RF and MMP-3 and the response to biologics treatment in RA patients. Although our results did not reach statistical significance, high RF titers ${ }^{28}$ or the presence of RF itself ${ }^{26}$ were shown in two studies to be factors predicting a poor treatment response. On the other hand, Bruns et al demonstrated no association of responses against biologics with RF titers as well as ACPA titers. ${ }^{25}$ In addition, Visvanathan et al showed that basal MMP-3 levels may predict clinical improvement in clinical responses and also in structural damage after 1 year of IFX plus MTX treatments. ${ }^{29}$ These conflicting results might be resolved by the analysis of a large number of biologics-naive RA patients with longterm observation. Taken together, because moderate or better treatment responses were confirmed in all of the ACPA-negative RA patients, we conclude that an adequate treatment response could be expected for patients who are negative for serum ACPA before treatment. 


\section{A}

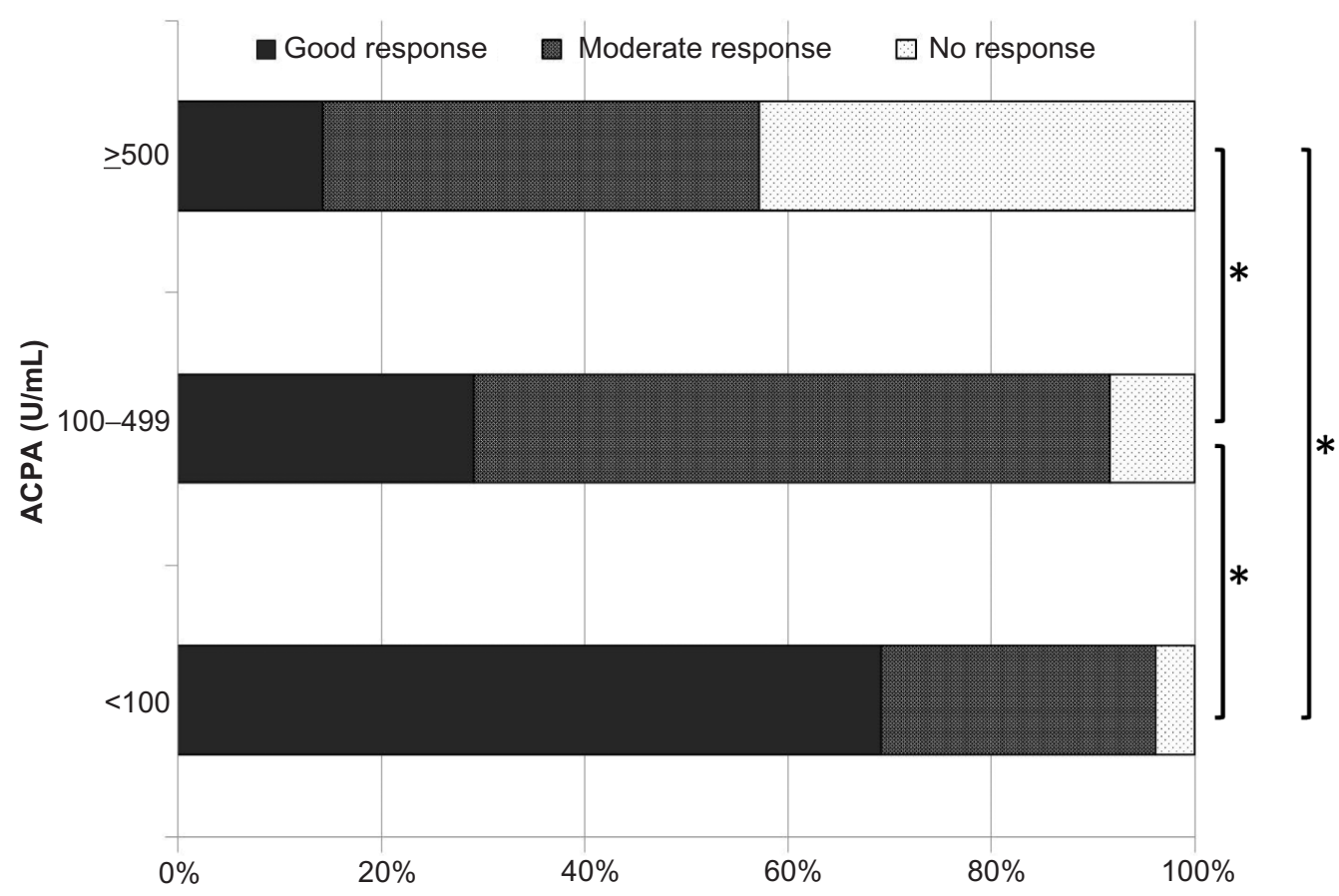

B

Remission No remission

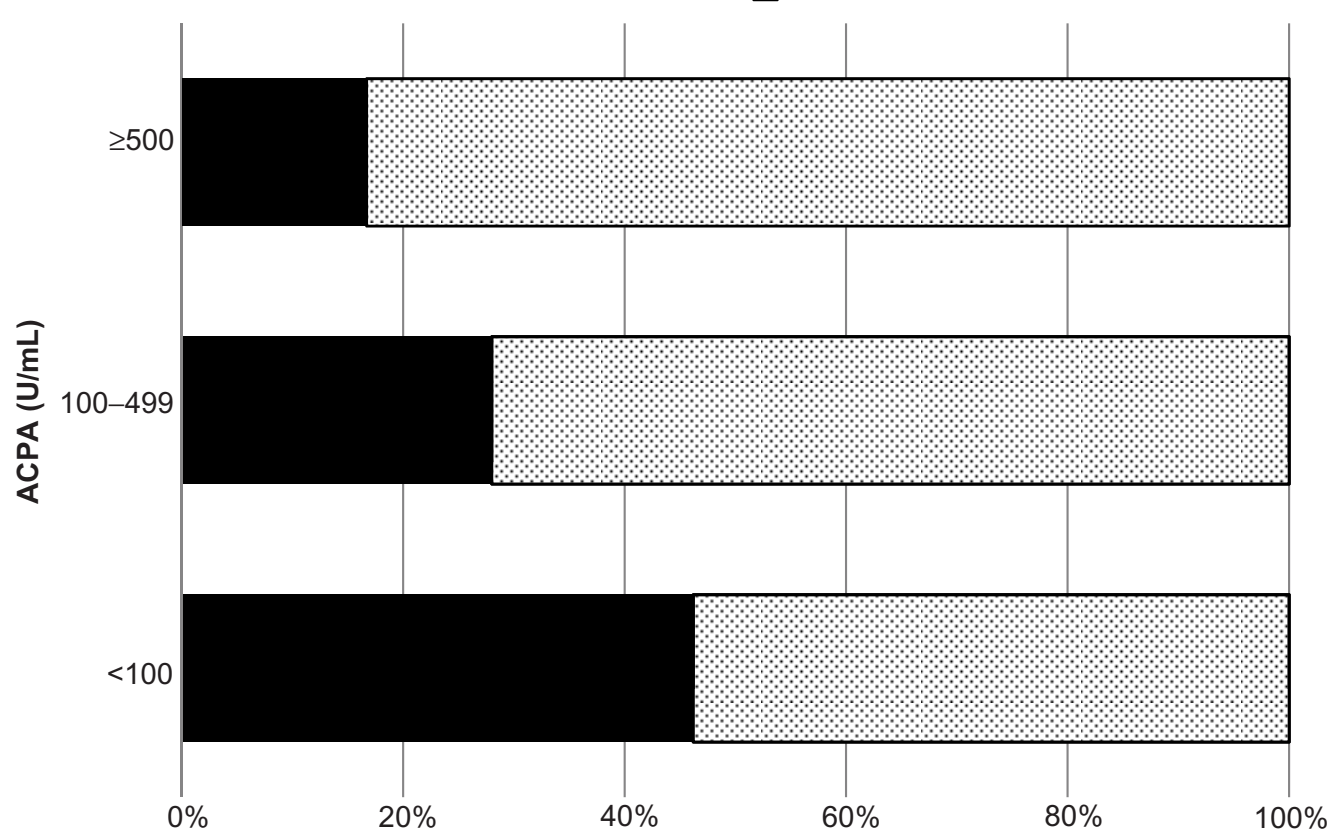

Figure 2 Comparison of the response rate between basal levels of ACPA titers.

Notes: Based on basal ACPA levels, the patients were divided into a low titer group with ACPA $<100 \mathrm{U} / \mathrm{mL}$ ( $\mathrm{n}=26$ ), a moderate titer group with ACPA = $100-499 \mathrm{U} / \mathrm{mL}$ $(n=24)$, and a high titer group with $A C P A \geq 500 \mathrm{U} / \mathrm{mL}(n=7)$, and treatment responses $(\mathbf{A})$ and remission rates (B) were compared among these three groups. Higher basal ACPA levels were associated with no response to treatment; $* P<0.01$.

Abbreviation: ACPA, anticyclic citrullinated protein antibody.

The involvement of genetic background in RA development and ACPA has also been investigated in recent years. The prevalence of the human leukocyte antigen (HLA)-DRB1*0405, one of the HLA-DRB1 genotypes, was reported in $47 \%$ of ACPA-positive patients, a rate significantly higher than that in controls. ${ }^{30,31}$ Furthermore, Terao et al performed similar genetic analyses based on positivity for ACPA and $\mathrm{RF}^{32}$ In this report, the ACPA(-), RA(+) group showed correlations with DRB1*0405 and 0901, whereas the ACPA(-), $\mathrm{RF}(-)$ group showed correlations 
Table 4 Rate of clinical responses between the ACPA-positive and -negative groups

\begin{tabular}{lll}
\hline Responses & $\begin{array}{l}\text { ACPA-positive } \\
(\mathbf{n = 4 8 )}\end{array}$ & $\begin{array}{l}\text { ACPA-negative } \\
(\mathbf{n}=\mathbf{9})\end{array}$ \\
\hline Good response & 18 & 7 \\
Moderate response & 23 & 2 \\
No response & 7 & 0 \\
Remission & 12 & 7 \\
No remission & $36^{*}$ & 2 \\
\hline
\end{tabular}

Notes: The remission rate in the ACPA-negative group was $77.8 \%$ (7/9), which was significantly higher than the rate of $25 \%(12 / 48)$ in the ACPA-positive group $* P<0.005$ by Fisher's exact probability test.

Abbreviation: ACPA, anticyclic citrullinated protein antibody.

with HLA-DR14 and HLA-DR8. Based on these results, it is reasonable to speculate that the presence of ACPA and RF may represent a portion of the spectrum of RA phenotypes, each of which may be an RA subtype with a different genetic background. Because the results of the present study also showed better treatment responses in the ACPA-negative than in the ACPA-positive patients, the production of ACPA may be affected by genetic or environmental factors. Further studies are needed to resolve this issue.

Four biological agents, IFX, ETN, ADA, and TCZ, were included in this study, and disease activities before and at the 14th week after administration of the biological agents were compared. By examining early responses to treatment with these biological agents, cases showing no effect or an attenuated effect of these agents, in other words, primary or secondary ineffectiveness, were excluded. After comparisons with other disease/inflammatory markers such as RF, MMP-3, CRP, and DAS28 we ultimately concluded that only ACPA can serve as an important factor for responses to treatment with biological agents in RA.

Our study has some limitations. First, the number and disease duration of patients was small and relatively long (mean 8.2 years); thus, larger scale studies are needed. Second, this study was based on the nonrandom assignment of treatments although there were no significant differences in patient background factors including DAS28 components and doses of MTX and prednisolone among the groups. Third, there is potential bias in the use of biological agents. IFX or ETN recipients accounted for $50 \%$ or more of the patients. Fourth, the follow-up period was relatively short (12-14 weeks). Further larger scale case studies with an increased number of patients receiving each biological agent may be warranted.

Taken together, if RA patients, even those unresponsive to DMARDs, are negative for ACPA, favorable responses to treatment with biological agents are likely to be achieved. However, because the effects against the biological agents seems to be insufficient in long-standing RA patients with a high pretreatment ACPA titer, therapeutic strategies may need to be developed and explained to RA patients with higher disease activity.

\section{Disclosure}

The authors report no conflicts of interest in this work.

\section{References}

1. Lee DM, Weinblatt ME. Rheumatoid arthritis. Lancet. 2001;358(9285): 903-911.

2. Jenkins JK, Hardy KJ, McMurray RW. The pathogenesis of rheumatoid arthritis: a guide to therapy. Am J Med Sci. 2002;323(4):171-180.

3. Scott DL, Wolfe F, Huizinga TW. Rheumatoid arthritis. Lancet. 2010; 376(9746):1094-1108.

4. Smolen JS, Landewé R, Breedveld FC, et al. EULAR recommendations for the management of rheumatoid arthritis with synthetic and biological disease-modifying antirheumatic drugs. Ann Rheum Dis. 2010;69(6): 964-975.

5. Weinblatt ME, Bathon JM, Kremer JM, et al. Safety and efficacy of etanercept beyond 10 years of therapy in North American patients with early and longstanding rheumatoid arthritis. Arthritis Care Res (Hoboken). 2011;63(3):373-382.

6. Tak PP, Kalden JR. Advances in rheumatology: new targeted therapeutics. Arthritis Res Ther. 2011;13(Suppl 1):S5.

7. Leombruno JP, Einarson TR, Keystone EC. The safety of antitumour necrosis factor treatments in rheumatoid arthritis: meta and exposure-adjusted pooled analyses of serious adverse events. Ann Rheum Dis. 2009;68(7):1136-1145.

8. Schellekens GA, de Jong BA, van den Hoogen FH, van de Putte LB, van Venrooij WJ. Citrulline is an essential constituent of antigenic determinants recognized by rheumatoid arthritis-specific autoantibodies. J Clin Invest. 1998;101(1):273-281.

9. Schellekens GA, Visser H, de Jong BA, et al. The diagnostic properties of rheumatoid arthritis antibodies recognizing a cyclic citrullinated peptide. Arthritis Rheum. 2000;43(1):155-163.

10. Chapuy-Regaud S, Sebbag M, Baeten D, et al. Fibrin deimination in synovial tissue is not specific for rheumatoid arthritis but commonly occurs during synovitides. J Immunol. 2005;174(8):5057-5064.

11. Zhao X, Okeke NL, Sharpe O, et al. Circulating immune complexes contain citrullinated fibrinogen in rheumatoid arthritis. Arthritis Res Ther. 2008;10(4):R94.

12. van Venrooij WJ, van Beers JJ, Pruijn GJ. Anti-CCP antibodies: the past, the present and the future. Nat Rev Rheumatol. 2011;7(7):391-398.

13. Nishimura K, Sugiyama D, Kogata Y, et al. Meta-analysis: diagnostic accuracy of anti-cyclic citrullinated peptide antibody and rheumatoid factor for rheumatoid arthritis. Ann Intern Med. 2007;146(11):797-808.

14. Aggarwal R, Liao K, Nair R, Ringold S, Costenbader KH. Anti-citrullinated peptide antibody assays and their role in the diagnosis of rheumatoid arthritis. Arthritis Rheum. 2009;61(11):1472-1483.

15. Nielen MM, van Schaardenburg D, Reesink HW, et al. Specific autoantibodies precede the symptoms of rheumatoid arthritis: a study of serial measurements in blood donors. Arthritis Rheum. 2004;50(2): 380-386.

16. Kroot EJ, de Jong BA, van Leeuwen MA, et al. The prognostic value of anti-cyclic citrullinated peptide antibody in patients with recent-onset rheumatoid arthritis. Arthritis Rheum. 2000;43(8):1831-1835.

17. Meyer O, Labarre C, Dougados M, et al. Anticitrullinated protein/ peptide antibody assays in early rheumatoid arthritis for predicting five year radiographic damage. Ann Rheum Dis. 2003;62(2):120-126.

18. Berglin E, Johansson T, Sundin U, et al. Radiological outcome in rheumatoid arthritis is predicted by presence of antibodies against cyclic citrullinated peptide before and at disease onset, and by IgA-RF at disease onset. Ann Rheum Dis. 2006;65(4):453-458. 
19. Syversen SW, Gaarder PI, Goll GL, et al. High anti-cyclic citrullinated peptide levels and an algorithm of four variables predict radiographic progression in patients with rheumatoid arthritis: results from a 10-year longitudinal study. Ann Rheum Dis. 2008;67(2):212-217.

20. van den Broek M, Dirven L, Klarenbeek NB, et al. The association of treatment response and joint damage with ACPA-status in recent-onset RA: a subanalysis of the 8-year follow-up of the BeSt study. Ann Rheum Dis. 2012;71(2):245-248.

21. Arnett FC, Edworthy SM, Bloch DA, et al. The American Rheumatism Association 1987 revised criteria for the classification of rheumatoid arthritis. Arthritis Rheum. 1988;31(3):315-324.

22. Welsing PM, van Riel PL. The Nijmegen inception cohort of early rheumatoid arthritis. J Rheumatol. 2004;31(69):14-21.

23. Braun-Moscovici Y, Markovits D, Zinder O, et al. Anti-cyclic citrullinated protein antibodies as a predictor of response to anti-tumor necrosis factor-alpha therapy in patients with rheumatoid arthritis. J Rheumatol. 2006;33(3):497-500.

24. Bos WH, Bartelds GM, Wolbink GJ, et al. Differential response of the rheumatoid factor and anticitrullinated protein antibodies during adalimumab treatment in patients with rheumatoid arthritis. J Rheumatol. 2008;35(10):1972-1977.

25. Bruns A, Nicaise-Roland P, Hayem G, et al. Prospective cohort study of effects of infliximab on rheumatoid factor, anti-cyclic citrullinated peptide antibodies and antinuclear antibodies in patients with longstanding rheumatoid arthritis. Joint Bone Spine. 2009;76(3):248-253.

26. Potter C, Hyrich KL, Tracey A, et al; BRAGGSS. Association of rheumatoid factor and anti-cyclic citrullinated peptide positivity, but not carriage of shared epitope or PTPN22 susceptibility variants, with anti-tumour necrosis factor response in rheumatoid arthritis. Ann Rheum Dis. 2009;68(1):69-74.
27. Klaasen R, Cantaert T, Wijbrandts CA, et al. The value of rheumatoid factor and anti-citrullinated protein antibodies as predictors of response to infliximab in rheumatoid arthritis: an exploratory study. Rheumatology (Oxford). 2011;50(8):1487-1493.

28. Bobbio-Pallavicini F, Caporali R, Alpini C, et al. High IgA rheumatoid factor levels are associated with poor clinical response to tumour necrosis factor alpha inhibitors in rheumatoid arthritis. Ann Rheum Dis. 2007;66(3):302-307.

29. Visvanathan S, Marini JC, Smolen JS, et al. Changes in biomarkers of inflammation and bone turnover and associations with clinical efficacy following infliximab plus MTX therapy in patients with early rheumatoid arthritis. J Rheumatol. 2007;34(7):1465-1474.

30. Furuya T, Hakoda M, Ichikawa N, et al. Differential association of HLA-DRB1 alleles in Japanese patients with early rheumatoid arthritis in relationship to autoantibodies to cyclic citrullinated peptide. Clin Exp Rheumatol. 2007;25(2):219-224.

31. Uçar F, Çapkin E, Karkucak M, et al. Associations of HLA-DRB1 alleles with anti-citrullinated protein antibody-positive and anti-citrullinated protein antibody-negative rheumatoid arthritis in northern east part of Turkey. Int J Rheum Dis. 2012;15(6):538-545.

32. Terao C, Ohmura K, Ikari K, et al. ACPA-negative RA consists of two genetically distinct subsets based on RF positivity in Japanese. PLoS One. 2012;7(7):e40067.
Open Access Rheumatology Research and Reviews

\section{Publish your work in this journal}

Open Access Rheumatology Research and Reviews is an international, peer-reviewed, open access journal, publishing all aspects of clinical and experimental rheumatology in the clinic and laboratory including the following topics: Pathology, pathophysiology of rheumatological diseases; Investigation, treatment and management of rheumatological

\section{Dovepress}

diseases; Clinical trials and novel pharmacological approaches for the treatment of rheumatological disorders. The manuscript management system is completely online and includes a very quick and fair peerreview system, which is all easy to use. Visit http://www.dovepress.com/ testimonials.php to read real quotes from published authors. 